\title{
A evasão na educação superior: definições e trajetórias
}

\author{
Camila Lima Coimbra ${ }^{1}$ \\ ORCID: 0000-0002-7755-9473 \\ Leonardo Barbosa e Silva ${ }^{1}$ \\ ORCID: 0000-0002-1528-1445 \\ Natália Cristina Dreossi Costa ${ }^{1}$ \\ ORCID: 0000-0003-3029-6466
}

\section{Resumo}

Considera-se o fenômeno da evasão uma das principais preocupações do Ministério da Educação, visto como um alvo a ser combatido ou um índice a ser reduzido. 0 termo aparece em algumas políticas públicas para o Ensino Superior, tais como Reuni (BRASIL, 2007), o Sinaes (BRASIL, 2004) e o Pnaes (BRASIL, 2010). No entanto, a pesquisa bibliográfica feita para mapeamento de uma pesquisa maior denominada: Evasão, retenção e permanência: inclusão social e direito à educação revelou que as análises de especialistas e os documentos oficiais têm mostrado divergências e/ou insuficiências e reunido fenômenos de naturezas diferentes. Têm assentado a divergência sobre critérios que quase nunca se diferenciam pela causalidade ou pela motivação da perda de vínculo com a instituição. Com efeito, o objetivo deste artigo caminha no sentido de apontar os limites das definições vigentes acerca da evasão no Ensino Superior Federal, reforçar a importância das definições a partir das causalidades e, finalmente, alcançar uma definição apropriada de evasão para formulação e avaliação de políticas para o Ensino Superior Federal. Para isso, optou-se por fazer um mapeamento da produção bibliográfica a respeito da temática, um breve resgate dos documentos oficiais acerca do tema e da bibliografia especializada e, em seguida, lançar sugestão para o debate acerca da evasão, na compreensão desse fenômeno como um indicador social.

\section{Palavras-chave}

Evasão - Ensino superior - Políticas públicas.

1- Universidade Federal de Uberlândia, Uberlândia, Minas Gerais. Brasil.

Contatos: camila.coimbra@ufu.br; barbosaesilva.leonardo@ufu.br; nataliadreossi@gmail.com

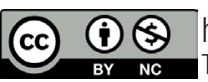




\section{Evasion in higher education: definitions and trajectories*}

\section{Abstract}

The evasion phenomenon is considered one of the Ministry of Education main concerns and seen as a target to be tackled or an index to be reduced. The term appears in some public policies for Higher Education, such as REUNI (BRASIL, 2007), SINAES (BRASIL, 2004) and PNAES (BRASIL, 2010). However, the bibliographic research done in order to map a larger search called: Evasion, retention and permanence: social inclusion and the right to education has revealed that expert analysis and official documents are showing divergences and/or insufficiencies and brought together phenomena of different kind. The divergence has been based on criteria that almost never differentiated by causality or motivation for loss of bond with the institution. Indeed, the purpose of this article moves towards pointing out the limits of the current definitions about evasion in Federal Higher Education, reinforcing the importance of definitions based on causalities and, finally, reaching an appropriate definition of evasion for the formulation and evaluation of policies for Federal Higher Education. For this, it was decided to make a mapping of the bibliographic production on the subject, a brief retrieval of official documents about the topic and the specialized bibliography and then launch a suggestion for the debate about evasion, in the understanding of this phenomenon as a social indicator.

\section{Keywords}

Evasion - Higher education - Public policies.

\section{Introdução}

A evasão figura entre as principais atenções do Ministério da Educação (MEC), em quaisquer níveis de ensino. Também se encontra presente como preocupação em várias políticas para o ensino superior federal, tais como os Planos de Reestruturação e Expansão das Universidades Federais - Reuni (BRASIL, 2007), o Sistema Nacional de Avaliação da Educação Superior - Sinaes (BRASIL, 2004) e o Plano Nacional de Assistência Estudantil - Pnaes (BRASIL, 2010), tornando-se um alvo a ser batido ou um índice a ser reduzido, sobretudo por representar, de alguma forma, o fracasso institucional.

Toma-se por pressuposto que as políticas de combate à evasão, assim como quaisquer outras políticas públicas, devem partir de um diagnóstico, ou de uma apreciação (HOWLETT; RAMESH; PERL, 2013) na qual se consideram os dados e as evidências acerca do problema social. Esteve na mira dos gestores dessas políticas, seguramente, o volume, a natureza, a causalidade referentes ao fenômeno do desligamento do ensino superior. Todavia, o 
levantamento bibliográfico feito para esta pesquisa revelou certo nível de dissonância entre o que se tem nominado, mensurado e explicado. Nesse instante, parecem emergir três perguntas relevantes. A primeira, no campo da definição, inquere o que se chama de evasão no ensino superior federal. A segunda, claramente dependente da primeira, atenta à sua extensão, reclama saber sobre seu tamanho e seus números. E, por fim, a última, já mais avançada e afeita a etapas superiores de formulação, procuraria buscar soluções.

Este artigo está especialmente interessado no primeiro aspecto, mais especificamente na importância de uma definição apropriada de evasão para a formulação e avaliação de políticas para o ensino superior federal, pois sem ela a mensuração e quantificação não se apropriarão inequivocamente do fenômeno, bem como as políticas formuladas não terão um alvo bem definido. 0 que justifica um artigo dedicar-se à definição da evasão é, justamente, o fato de que a bibliografia e os documentos oficiais têm mostrado divergência e reunido fenômenos de naturezas diferentes. E, talvez a dimensão mais preocupante, têm assentado a divergência a respeito de critérios que quase nunca se diferenciam pela causalidade ou pela motivação da perda de vínculo com a instituição. Via de regra, são enfatizadas as formas e negligenciadas as razões que animam o desligamento. A razão da evasão, crê-se, só poderia ser extraída de levantamentos com egressos, que quase nunca aparecem para subsidiar as reflexões do campo.

0 resultado, como se poderia esperar, são definições genéricas, abarcando quase todo tipo de perda de vínculo como evasão. Levando para a mesma conta falecimentos, troca de cursos, expulsões, jubilamentos, saída por ausência de vocação, por problemas financeiros, por problemas curriculares, por adoecimento, entre tantos outros. Cada uma dessas razões pode ou não representar um problema, bem como cada uma delas pode exigir um tipo de abordagem, de mensuração e de política pública.

Com efeito, o objetivo deste artigo é apontar os limites das definições vigentes acerca da evasão no ensino superior federal, reforçar a importância das definições a partir das causalidades e, finalmente, trazer uma sugestão para o debate. Por isso, o primeiro desafio teórico seria definir a evasão, isto é, dar o seu significado direto, preciso e normativo, para que se identifiquem seus casos. Optou-se por apresentar o texto em duas partes, antes das considerações finais. De um lado, um rápido sobrevoo por parte dos documentos oficiais acerca do tema e da bibliografia especializada e, de outro, a sugestão de uma nova definição para evasão a partir de suas causalidades.

\section{A evasão nos marcos regulatórios: imprecisões}

0 recorte definido para este artigo data de três importantes marcos legais, a Lei de Diretrizes e Bases da Educação Nacional de 1996, a institucionalização do Sistema de Avaliação da Educação Superior, a partir de 2004, e o Programa de Apoio a Planos de Reestruturação e Expansão das Universidades Federais - Reuni, a partir de 2007. Em que essas três legislações influenciam em uma definição de evasão? Quais definições trazem?

Cabe, primeiramente, problematizar essa leitura recorrendo ao que de fato representaria o objetivo da Educação Superior. De acordo com o artigo 43, da LDB - Lei 
de Diretrizes e Bases da educação (Lei nº 9.394/96), as finalidades da Educação Superior seriam precisamente:

I - estimular a criação cultural e o desenvolvimento do espírito científico e do pensamento reflexivo; II - formar diplomados nas diferentes áreas de conhecimento, [...]; III - incentivar o trabalho de pesquisa e investigação científica, visando o desenvolvimento da ciência e da tecnologia e da criação e difusão da cultura, e, desse modo, desenvolver o entendimento do homem e do meio em que vive; IV - promover a divulgação de conhecimentos culturais, científicos e técnicos que constituem patrimônio da humanidade e comunicar o saber através do ensino, de publicações ou de outras formas de comunicação; V - suscitar o desejo permanente de aperfeiçoamento cultural e profissional [...]; VI - estimular o conhecimento dos problemas do mundo presente, [...]; VII - promover a extensão, aberta à participação da população, [...]; VIII - atuar em favor da universalização e do aprimoramento da educação básica, [...]. (BRASIL, 1996, n.p).

Assim, a Lei 9.394/96 não elenca as finalidades da Educação Superior de forma hierárquica ou condicionada, levando-se a crer que o interesse do legislador foi conferir igualdade a elas. Sendo isso verdade, merece destaque o fato de que das oito finalidades, somente uma diz respeito estritamente à diplomação para o trabalho, a segunda. Em todas as demais, é possível que o estudante as desenvolva durante seu curso de forma plena ou quase plena sem, necessariamente, obter seu diploma. Isso não se deve ao fato de a LDB ser negligente quanto à diplomação, mas sim ao de não reduzir a atividade universitária à fabricação de diplomados ou à formação de força de trabalho. Isto posto, o conteúdo da referida lei atribui à universidade um papel destacado no processo civilizatório, na direção de uma sociedade mais justa, democrática, desenvolvida e plural. A avaliação do sucesso ou fracasso universitário deveria, rigorosamente, levar em consideração a totalidade das finalidades, sem a redução à dimensão do mercado. Da mesma maneira, quaisquer outros fenômenos universitários, tal como a evasão, deveriam ser submetidos aos juízos levando em consideração a gama de fins a que o sistema se destina.

Por seu turno, a Lei n 10.861/2004 que institui o Sistema Nacional de Avaliação da Educação Superior - Sinaes foi um importante marco legal, pois sistematizou as bases e fundamentos para a criação de uma política de avaliação da Educação Superior, com os seguintes objetivos:

[...] a melhoria da qualidade da educação superior, a orientação da expansão da sua oferta, o aumento permanente da sua eficácia institucional e efetividade acadêmica e social e, especialmente, a promoção do aprofundamento dos compromissos e responsabilidades sociais das instituições de educação superior, por meio da valorização de sua missão pública, da promoção dos valores democráticos, do respeito à diferença e à diversidade, da afırmação da autonomia e da identidade institucional. (BRASIL, 2004, n.p., grifos nossos).

Efıcácia e efetividade são termos utilizados aqui para definir a melhoria da qualidade da Educação Superior, tais termos, apesar de parecerem sinônimos, trazem diferenças em suas defınições, pois requereria dessa legislação a defınição a que se refere. 
Normalmente seu uso é intensivo em programas de avaliação de políticas públicas, como explicam Costa e Castanhar (2003) acerca das orientações da Unicef (Fundo das Nações Unidas para a Infância). Em consonância com Costa e Castanhar (2003), reconhece-se como acertada para o objeto a orientação da Unicef para o estabelecimento de critérios de: a) eficiência, b) eficácia, c) efetividade (impactos), d) satisfação de usuário, e) análise de custo-efetividade, f) sustentabilidade e g) equidade. A eficiência, nessa perspectiva, avalia a melhor relação custo/benefício possível para o alcance dos objetivos estabelecidos no programa. A eficácia, de acordo com os autores, avalia o grau em que o programa atinge os seus objetivos e metas. E, por fim, a efetividade: avalia se o projeto tem efeitos (positivos) no ambiente externo em que interveio, em termos técnicos, econômicos, socioculturais, institucionais e ambientais. Parecem definições com dimensão técnica, mas são importantes na criação de um sistema de avaliação, por isso a necessidade de definir esses termos.

Apesar da ausência de uma definição explícita na Lei, utilizam-se essas definições para compreender os critérios e os princípios de tal melhoria da qualidade: a responsabilidade social das Instituições de Ensino Superior. Esse aspecto fica latente quando se propõe a avaliar o conceito de evasão, pois não se pode, a partir desse cenário, dissociá-lo dessa responsabilidade anunciada na Lei.

Reiterando o que se analisou acima, o texto da Lei apresenta, em seu artigo $3^{\circ}$, as dimensões institucionais que devem ser consideradas no âmbito da avaliação, sendo que, dentre elas, estão duas consideradas muito relevantes para esse contexto da evasão:

[...] a responsabilidade social da instituição, considerada especialmente no que se refere à sua contribuição em relação à inclusão social, ao desenvolvimento econômico e social, à defesa do meio ambiente, da memória cultural, da produção artística e do patrimônio cultural e, a dimensão de políticas de atendimento estudantil. (BRASIL, 2004, n.p. grifo nosso).

0 que se pretende demonstrar por meio deste marco regulatório é que a criação de um sistema de avaliação da educação superior está intimamente relacionada aos fins e princípios de sua instituição e que, os mesmos, já estão declarados na legislação nacional, como dimensões de seu processo avaliativo.

Mas qual a relação entre o conceito de evasão e a legislação do Sinaes? A relação estabelece-se por meio do princípio. Não há como definir a evasão sem que esteja claro de qual referencial partimos. Assim, estabelecemos este como o segundo marco regulatório em que nos apropriaremos dos seguintes princípios: responsabilidade social, valores democráticos, respeito à diferença e à diversidade, na direção de uma sociedade mais justa. Esses princípios legais estão associados a uma visão de Universidade em que os(as) estudantes são protagonistas. Nessa perspectiva, os(as) estudantes são a razão das atividades meio e das atividades fins das Instituições, portanto, ancora-se nos princípios do Sinaes, com o detalhamento do lugar em que se enxerga a categoria estudantil no âmbito das universidades públicas brasileiras.

Vale destacar ainda que dos documentos que compõem o Sinaes, as "Orientações Gerais para o roteiro da autoavaliação das Instituições” (2004), a palavra evasão aparece 
duas vezes. A primeira refere-se à descrição das ações planejadas pelas IES em que a "definição da composição dos grupos de trabalho, atendendo aos principais segmentos da comunidade acadêmica (avaliação de egressos e/ou dos docentes; estudo de evasão etc)” (BRASIL, 2004, p. 10) apresenta-se como uma das ações. 0 estudo de evasão, neste caso, é responsabilidade dos grupos de trabalho a serem criados pelas IES em sua autoavaliação. A segunda vez, a palavra aparece no item "Políticas de atendimento aos estudantes" em que se apresentam como parte do núcleo básico e comum:

Mecanismos/sistemáticas de estudos e análises dos dados sobre ingressantes, evasão/ abandono, tempos médios de conclusão, formaturas, relação professor/aluno e outros estudos tendo em vista a melhoria das atividades educativas. (BRASIL, 2004, p. 33).

A fragilidade do Sinaes em relação à evasão consiste na inexistência de algum indicador avaliativo e/ou critério de análise que consiga identificar e avaliar os dados institucionais sobre a evasão em nenhum dos 5 eixos do Instrumento de Avaliação Institucional Externa (2017). Na autoavaliação aparece como uma ação institucional, mas não será avaliado em outro momento pelo Sinaes. Talvez essa incoerência provoque as questões teóricas e metodológicas que apontaremos neste artigo. Pouco aparece em documentos norteadores, mas ao mesmo tempo, apresenta-se como um número importante para o orçamento público na Educação Superior.

Apesar das ausências anunciadas, associa-se a esse marco regulatório o Decreto nº 6.096/2007, que institui o Programa de Apoio a Planos de Reestruturação e Expansão das Universidades Federais - Reuni que traz em suas diretrizes:

I- redução das taxas de evasão, ocupação de vagas ociosas e aumento de vagas de ingresso, especialmente no período noturno; II- ampliação da mobilidade estudantil, com a implantação de regimes curriculares e sistemas de títulos que possibilitem a construção de itinerários formativos, mediante o aproveitamento de créditos e a circulação de estudantes entre instituições, cursos e programas de educação superior; [...] V - ampliação de políticas de inclusão e assistência estudantil; [...]. (BRASIL, 2007, n.p., grifo nosso).

A partir desse referencial, abre-se a necessidade e o acompanhamento das Instituições que aderiram ao Reuni, por meio da redução das taxas de evasão e ampliação da mobilidade estudantil, o que anuncia uma definição em que se compreenda e se diferencie evasão de mobilidade. Com efeito, ainda que o programa de expansão das instituições federais objetive reduzir as taxas de evasão, não se tem clara a definição da própria evasão. Por mais que se recorram às cartilhas, documentos complementares à implementação, não se encontrará a precisão do termo. Desse modo, indefinido, as instituições federais ficam à sorte de suas próprias elaborações, sem que uma orientação geral lhes traga luz para saber o que mensurar e o que combater.

Assim, esses três marcos regulatórios, a saber a Lei no 9.394/96 (LDB), a Lei $n^{\circ} 10.861 / 04$ (Sinaes) e o Decreto $n^{\circ}$ 6.096/2007 (Reuni), com suas ausências e 
presenças pretendem ser a referência para a análise e definição da evasão, objetivo que passamos a cumprir na próxima seção.

\section{Levantamento bibliográfico: definições e concepções}

Inicialmente, interessa apresentar um sintético mapeamento da produção bibliográfica encontrada acerca da evasão. Sua feição média apresenta um flagrante predomínio de estudos de casos que cobrem estados, instituições ${ }^{2}$, cursos $^{3}$ ou categorias de discentes. Ademais, com maior dificuldade são encontrados trabalhos com abordagens nacionais e pretensões totalizantes ${ }^{4}$, bem como revisões da bibliografia do campo ${ }^{5}$.

Antes do levantamento, tinha-se a expectativa de encontrar um número mais volumoso de trabalhos em periódicos, sobretudo porque se partia da concepção de que a evasão é uma temática recorrente na atenção de gestores de Instituições Federais de Ensino Superior - IFES, de suas associações e do próprio Ministério da Educação. Em 2017, em pesquisa ao portal Scielo (www.scielo.br) utilizando as chaves de busca evasão e ensino superior para qualquer campo se consegue 14 artigos como resposta. Quando a mesma pesquisa é feita na base de dados da CAPES (www.catalogodeteses.capes.gov.br), o número de estudos é impressionante, uma vez que são 97.821 dissertações de mestrado e 28.843 teses de doutorados. Uma rápida observação pela lista de títulos permite perceber que novamente são predominantes os estudos de caso.

Inicialmente, é constatável que a maioria das definições usa expressões diferentes, mas alinha-se na descrição da evasão como sendo simplesmente a perda de vínculo, a saída da instituição, o abandono do curso, o desligamento - do curso, instituição ou sistema, sejam eles atos voluntários ou não.

Das definições apresentadas, somente Bueno (1993), Ristoff (1999) e, parcialmente ${ }^{6}$, Cardoso (2008) advertem que as perdas de vínculo exigem matização, distinguindo os fenômenos e separando-os entre problemas ou não. Problemas para as políticas públicas são situações indesejadas para os quais a coletividade vislumbra melhoria, afinal, uma política pública nasce para fazer oposição a um problema público (SECCHI, 2016). Com efeito, por qual outra razão nos preocuparíamos com a perda de vínculo de estudantes com o sistema universitário? Ora, somente se a perda de vínculo representar, em alguma proporção, um problema público.

Em um caso modelar, para Silva Filho et al. (2007), toda evasão representa desperdícios sociais, acadêmicos e econômicos. Presos à ideia de que o investimento público fora realizado objetivando a conclusão ou a diplomação, os autores reclamam o devido retorno do gasto, condenando quaisquer perdas de vínculos.

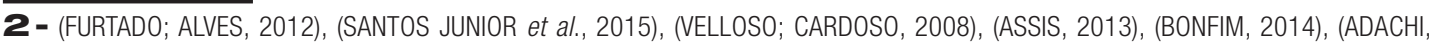
2009), (DAVOK; BERNARD, 2016), (VELOSO; ALMEIDA, 2013), (SANTOS JUNIOR et al., 2016), (RODRIGUEZ, 2011), (SANTOS JUNIOR, 2015a).

3 - (CORREAA; NORONHA; MIURA, 2004), (ALMEIDA; SCHIMIGUEL, 2012), (RANGEL et al., 2013), (CAMPELLO; LINS, 2008).

4 - (AMBIEL, 2015; COMISSÃO ESPECIAL DE ESTUDOS SOBRE EVASÃO, 1996), (GILIOLI, 2016), (RISTOFF, 1999), (SANTOS; SILVA, 2011), (SANTOS JUNIOR, 2015b), (SILVA FILHO et al., 2007).

5- (BAGGl; LOPES, 2011), (BARDAGl; HUTZ, 2014).

6 - Diz-se parcialmente, porque reconhece a distinção entre evasão e mobilidade, mas usa ambas para analisar a evasão total.
} 
Quadro 01 - Lista de obras e suas definições de evasão

\begin{tabular}{c:c}
\hline OBRA & DEFINIÇÃo \\
\hline TINTO (1975) & $\begin{array}{c}\text { Ao que tudo indica, boa parte dos estudos sobre evasão toma o artigo de } 1975 \text { de Vicent Tinto como } \\
\text { uma referência (BARDAGl; HUTZ, 2014), cujo foco estava na análise interacional, buscando as raízes } \\
\text { da evasão na relação entre fatores externos, fatores pessoais, desaguando no nível de integração } \\
\text { social e acadêmica. Paralelo com a anomia e o suicídio. }\end{array}$ \\
\hline BUENO (1993) & $\begin{array}{r}\text { A palavra evasão pode estar significando uma postura ativa do aluno que decide desligar-se por sua } \\
\text { própria responsabilidade. A palavra exclusão implica a admissão de uma responsabilidade da escola e } \\
\text { de tudo que a cerca por não ter mecanismos de aproveitamento e direcionamento do adolescente que } \\
\text { se apresenta para uma formação profissionalizante. }\end{array}$ \\
\hline
\end{tabular}

1) Evasão de curso seria aquela que ocorre quando o estudante se desliga do curso superior em

Comissão especial de estudos sobre evasão (1996, p. 56)

\begin{tabular}{c:c} 
& $\vdots$ \\
$\operatorname{KIRA}(1998)$ & $\vdots$ \\
\hline $\operatorname{RISTOFF}(1999$, p. 127-8) & $\vdots$ \\
\hline
\end{tabular}

\begin{tabular}{c:c}
\hline POLYDORO (2000) & $\begin{array}{c}\text { Evasão do curso, quando se abandona o curso sem sua conclusão e a evasão do sistema, quando o } \\
\text { abandono se refere ao sistema universitário. }\end{array}$ \\
\hline
\end{tabular}

\begin{tabular}{c:cc}
\hline GAIOSO (2005) & Interrupção no ciclo de estudos \\
\hline ABBAD; SILVEIRA CARVALHO; & "Desistência definitiva do aluno em qualquer etapa do curso" \\
ZERBINI (2006) & & (20)
\end{tabular}

As perdas de estudantes que iniciam, mas não terminam seus cursos são desperdícios sociais, acadêmicos e econômicos. No setor público, são recursos públicos investidos sem o devido retorno. A evasão anual média mensura qual a percentagem de estudantes matriculados em um sistema SILVA FILHO et al. (2007) $\quad$ de ensino, em uma IES, ou em um curso que, não tendo se formado, também não se matriculou no ano seguinte (ou no semestre seguinte, se o objetivo for acompanhar o que acontece em cursos semestrais). A evasão total mede o número de estudantes que, tendo entrado num determinado curso, IES ou sistema de ensino, não obteve o diploma ao final de um certo número de anos.

"A evasão aparente refere-se aos alunos que saíram da universidade sem a conclusão do curso e sem formalizar transferência para outra universidade. Já a mobilidade é a troca de curso dentro da CARDOSO (2008) própria instituição ou a transferência para outra IES, ambas registradas na UnB. Somados estes dois tipos, temos o que poderíamos chamar de evasão total, a que geralmente é divulgada nas estatísticas sobre abandono".

Considerou-se como evadidos os casos de estudantes desligados dos cursos tanto por solicitação da instituição quanto por solicitação do estudante e, por formados, aqueles estudantes que, dentro das normas acadêmicas e cumpridos os prazos de integralização curricular, obtiveram a graduação cursada. Os casos de ingressantes que efetivaram algum tipo de transferência interna, seja, por meio dos processos de reopção de curso e/ou de turno, e que concluíram seus cursos, mesmo a UFMG não considerando como tal esta situação, todos foram tomados por evadidos. Considerou-se para tanto que a reopção de curso e de turno dependem da existência de vagas e desta maneira a ocupação de determinado lugar em um curso foi precedida por um desligamento de estudante.

\begin{tabular}{c|cc}
\hline JUNIOR et al. (2015) & Por estudante evadido entende-se aquele que abandona o curso antes de sua conclusão. \\
\hline BAGGl; LOPES (2011) & "saída do aluno da instituição antes da conclusão do seu curso" (p. 370). \\
\hline
\end{tabular}

Fonte: Elaboração própria. 
Assim sendo, estranha o fato de que boa parte da bibliografia especializada na evasão não a analise à luz das finalidades da educação superior, restringindo sua reflexão à manutenção do vínculo com um curso, uma instituição ou um sistema. Não obstante seja evidente o limite acima apontado, ao conduzir a reflexão para a simples perda do vínculo, a bibliografia também não a faz a partir de suas causas, de seus motivadores. Encontramse artigos, dissertações e teses que listam possíveis causas, outros até as colocam como objetos centrais, mas elas não afetam o próprio objeto, somente o decoram.

Crê-se que um bom ponto de partida seria tomar as ponderações de Dilvo Ristoff (1999). 0 autor atenta para o fato de que a evasão é um fenômeno normalmente analisado de forma isolada, como se tivesse vida própria e não guardasse relação com o resto da vida social e institucional. Em sua perspectiva, as análises dominantes veem a evasão como exclusão, como perda ou fuga, ignorando o que poderiam ser, na verdade, resultados das aspirações dos seres humanos que estão nas IFES e que nem sempre se alinham aos limites das nossas instituições. Destarte:

[...] parcela significativa do que chamamos de evasão, no entanto, não é exclusão, mas mobilidade, não é fuga, mas busca; não é desperdício, mas investimento; não é fracasso - nem do aluno, nem do professor, nem do curso ou da instituição - mas tentativa de buscar o sucesso ou a felicidade, aproveitando as relações que o processo natural de crescimento dos indivíduos faz sobre as suas verdadeiras potencialidades. (RISTOFF, 1997, p. 27).

0 que Ristoff (1997) advoga é que os atos de desligamento de um curso, instituição ou sistema de ensino podem conter uma infinidade de causas, dentre elas a própria opção por uma vida que não seja a universitária e que, por si só, seria legítima e poderia não expressar incapacidades institucionais. É razoável imaginar que um estudante troque de curso por razões variadas, mas a título de exemplo, poderíamos destacar o caso de um ingresso prematuro no ensino superior, ainda sem as noções mais importantes sobre a grade curricular, as oportunidades acadêmicas, os conhecimentos a serem acessados, as áreas de atuação e as condições de mercado de trabalho.

No decorrer dos primeiros semestres, em contato com outras experiências, a maior clareza poderia reorientar a escolha do curso. Por que razão a fuga de um curso para outro seria interpretada como um problema? Não seria admissível que um curso ideal, sem quaisquer insuficiências, seja preterido por outro em virtude de preferências tardiamente esclarecidas? E isso deve sinalizar um problema a ser combatido, mobilizando cérebros e recursos? Não se estaria apequenando a universidade e a vida ao levantarmos exércitos contra a mobilidade entre cursos?

\section{A evasão e suas causalidades: os porquês}

Em busca da caracterização do fenômeno a partir de sua causalidade, vale a pena utilizar o trabalho de Morosini (2009), que realizou um levantamento acerca da evasão em periódicos Qualis A e B entre os anos 2000 e 2011 e percebeu que em geral os artigos apontam como as principais causas da chamada "evasão": a) os aspectos financeiros 
relacionados à vida pessoal ou familiar do estudante; b) os aspectos relacionados à escolha do curso, expectativas pregressas ao ingresso, nível de satisfação com o curso e com a universidade; c) os aspectos interpessoais - dificuldades de relacionamento com colegas e docentes; d) os aspectos relacionados com o desempenho nas disciplinas e tarefas acadêmicas - índices de aprovação, reprovação e repetência; e) os aspectos sociais, como o baixo prestígio social do curso, da profissão e da universidade elegida; f) a incompatibilidade entre os horários de estudos com as demais atividades, como, por exemplo, o trabalho; g) os aspectos familiares como, por exemplo, responsabilidades com filhos e dependentes, apoio familiar quanto aos estudos etc.; e h) o baixo nível de motivação e compromisso com o curso.

Obviamente, essas oito principais causas recorrentes na bibliografia não encerrariam a lista de motivações. A quantidade de razões, sabe-se, é bem maior do que essa. Mesmo sem valer-se de pesquisa com egressos, portanto a título de hipótese, o Relatório Final da Comissão Especial criada pelo MEC em 1996 para diagnosticar o fenômeno (SESU/MEC; ANDIFES; ABRUEM, 1996) agrega as numerosas causas em três grandes grupos, quais sejam: a) fatores referentes a características individuais do estudante; b) fatores internos às instituições; e c) fatores externos às instituições.

São mais de 40 possíveis motivadores listados pela comissão. Não se sabe ao certo qual é o peso de cada um deles, tampouco sua variação espacial ou temporal. Somente pode-se concluir que, se ela estiver correta, são razões de naturezas muito distintas, exigindo diagnósticos e políticas igualmente distintos. Se um desligamento guarda relação direta com o currículo do curso, o diagnóstico e o prognóstico deverão apontar para as incompatibilidades e revisões necessárias, indicando como sujeito da ação a própria instituição de ensino. Todavia, se o problema está localizado no mercado de trabalho de determinada profissão, o que deve fazer a instituição? Se, porventura, a família do discente deslocou-se para outro território e obrigou a perda de vínculo, qual reflexão a universidade deve fazer sobre suas responsabilidades? Ou, de forma mais direta, onde está localizado seu fracasso? Portanto, antes de tudo se requer observar a evasão a partir de suas causas, separando o que seriam problemas públicos a serem enfrentados.

Mais do que isso, ainda partindo da suposição de que a Comissão acertou na hipótese das causações, não seria exagerado supor que alguns dos motivadores podem aparecer conjugados ocasionando o desligamento. Problemas familiares e pedagógicos concomitantes, individuais e institucionais aos pares, poderiam se somar, se alimentar e se impulsionar. Tal como nas desigualdades sociais, em que marcadores sociais como renda, cor da pele, gênero, orientação sexual etc., podem compor sistemas que se combinam e amplificam as iniquidades, os impulsionadores da perda de vínculo também. Nessas circunstâncias e dependendo da conjugação, a evasão deveria ser objeto concomitante de políticas de cursos diferentes, possivelmente Pró-reitorias diferentes, ou, quem sabe, até ministérios diferentes.

Entretanto, ao que parece, a distinção feita pela Comissão ainda nos exige reflexões. Primeiramente, é preciso que se diga, o levantamento da causalidade prescindiu de uma pesquisa com egresso, de modo que não se sabe com exatidão o que realmente causa a evasão no país. Por outro lado, a Comissão aloca motivadores cujos nexos causais 
parecem inapropriados. Vejamos, quando se referem a fatores externos, o relatório aponta, por exemplo, as dificuldades financeiras dos estudantes. Nesse ponto, é sabido que a assistência estudantil é uma política universitária cujo objetivo maior é garantir a permanência, combatendo as desigualdades e preservando o direito à educação (BRASIL, 2010b). Então, caso a evasão seja justificada pelas dificuldades financeiras do discente, estamos diante de um fator interno com vínculos externos, certamente. No entanto, nesse caso, não seria possível isentar a instituição.

Igualmente pode-se dizer de vários dos motivadores alocados nos fatores individuais. Para eles, a Comissão levou causas como problemas de aprendizado, dificuldades de relacionamento e baixo prestígio da universidade. Não demanda muito esforço imaginar que problemas de aprendizado podem derivar da prática pedagógica da instituição ou do (a) docente, ou que as dificuldades de relacionamento derivem de relações de assédio, ou mesmo que o desprestígio da instituição redunde de decisões equivocadas de gestores. Novamente, se está diante de uma categorização que não foi feliz na distinção e alocação dos motivadores.

\section{Fórmulas da evasão: como mensurar}

Deve-se não perder o foco daquilo que é central, isto é, as implicações de uma multiplicidade de fatores acerca de diagnósticos e mensurações do fenômeno da evasão. É nítido que não se pode produzir uma definição de evasão tão genérica que descreva simplesmente a perda do vínculo, porque essa definição não diz muito sobre o fenômeno. Tampouco se pode, a partir de uma definição assim, criar um indicador que quantifique o fenômeno, porque seus resultados também dirão pouco ou nada sobre o que se pretende saber. Aliás, poderão sim, como alerta Ristoff (1999), atiçar a leitura enviesada da crise da universidade. Acerca do debate sobre a mensuração do fenômeno, merece destaque a dissertação de mestrado de Freitas (2016), destinada a apresentar e analisar as diferentes formas de mensurar a evasão. 0 autor parte da constatação de que:

[...] o cálculo da evasão varia de acordo com a forma com que o conceito é definido. Quando a definição de evasão e a maneira pela qual é mensurada não são consistentes e claras, podem-se apresentar erros de interpretação, impossibilidade de comparações e, portanto, gerar riscos de decisões e encaminhamentos incorretos ou mesmo desnecessários. (FREITAS, 2016, apud LEHR et al., 2014, p. 14).

Por certo se tem que a mensuração da evasão quantificará o fenômeno que for definido como evasão. Ou seja, se for produzida uma definição vaga, capaz de abarcar fenômenos de naturezas diferentes, fatalmente contabilizar-se-ão ocorrências numerosas, díspares, imisciveis e, assim, insignificantes. Em concordância, Freitas (2016, p. 23) defende que:

[...] ao se pretender uma mudança nas ocorrências de fenômenos, como a diminuição do número de casos de evasão, é preciso buscar formas de intervenção, as quais devem se fundamentar no entendimento das causas, motivos ou condições associadas ao fenômeno. 
Com feliz acerto, Freitas (2016) percebe que parte dos instrumentos de mensuração da evasão toma como insumos os dados totais de graduações, dados agregados de ingressantes, vagas, concluintes etc., sem que se proceda ao acompanhamento individual de cada evadido. Isso posto, valendo-se de divisões entre numeradores e denominadores, as fórmulas tendem a apontar taxas ou percentuais de evasão, não raro entendidos como percentuais de sucesso ou fracasso. Outros, vislumbrando mensurar valores absolutos de evadidos e não taxas, recorrem aos mesmos insumos, valendo-se de dados agregados. Quando são usados tais dados para instrumentalizar o cálculo, é inevitável que se diluam as histórias, as trajetórias, as especificidades e, principalmente, as causas diferenciais.

Para facilitar a visualização das fórmulas, pode-se recorrer ao quadro abaixo que reúne as obras, suas definições de evasão e as respectivas fórmulas.

Quadro 02 - Balanço sobre a mensuração da evasão

\begin{tabular}{|c|c|c|}
\hline OBRA & DEFINIÇÃO & FÓRMULA \\
\hline Paredes (1994) & $\begin{array}{l}\text { Utiliza-se do "conceito de rendimento dos cursos", que é "calculado } \\
\text { como sendo a razão entre as graduações e as vagas ofertadas". }\end{array}$ & $\% E=100 \%-\frac{\text { Graduações }}{\text { vagas }}$ \\
\hline Silva Filho et al. (2007) & $\begin{array}{l}\text { A evasão total mede o número de estudantes que, tendo entrado } \\
\text { num determinado curso, IES ou sistema de ensino, não obteve o } \\
\text { diploma ao final de um certo número de anos. }\end{array}$ & $\begin{aligned} E_{n}=1-\left(M_{n}-\frac{1}{n}\right) & \left(M_{n-1}-C_{n-1}^{2}\right)\end{aligned}$ \\
\hline $\begin{array}{l}\text { Comissão especial de estudos } \\
\text { sobre evasão (1996) }\end{array}$ & $\begin{array}{c}\text { Estudantes que, ao fim do período da geração completa, não } \\
\text { haviam se diplomado e não estavam mais vinculados ao curso em } \\
\text { questão }\end{array}$ & $\% E=\underline{N}_{-}^{-N_{d}-N_{t}} \times 100$ \\
\hline Braga et al. (2003) & $\begin{array}{l}\text { Dados de turmas que ainda estavam dentro do tempo máximo } \\
\text { para integralização, sendo denominados por estes autores por } \\
\text { "geração incompleta". }\end{array}$ & $\begin{array}{l}\% \mathrm{E}=100 \%-\% \text { formandos- } \\
0,06 \times(100 \%-\% \text { formandos })\end{array}$ \\
\hline Serpa; Pinto (2000) & $\begin{array}{l}\text { Evadidos como a variação de matrículas excluindo ingressantes e } \\
\text { formados }\end{array}$ & $E_{x}=I_{x+1}-\left(M_{x+1}-M_{x}\right)-C_{x}$ \\
\hline
\end{tabular}

Fonte: Freitas (2016). Elaboração própria.

Não obstante se deva reconhecer o esforço intelectual, a sofısticação dos mecanismos de mensuração e sua legitimidade acadêmica e oficial (uma vez que utilizados por instituições de ensino, institutos de pesquisa e órgãos de implementação de políticas), todas as fórmulas partem da concepção de que a evasão é um resíduo, um produto da graduação incompleta e uma perda. Não se percebe em nenhuma delas a preocupação em discriminar quaisquer parcelas de perda de vínculo a partir de suas causalidades, novamente porque diluem todas as particularidades em um grande agregado.

Para perceber como isso se processa no nível local, isto é, em uma instituição federal de ensino superior, tomar-se-á como caso a Universidade Federal de Uberlândia - UFU. Em seu anuário, é possível visualizar a sinopse de seus principais números, dentre os quais se encontram as taxas de evasão. Para se chegar até elas, a instituição utiliza-se da fórmula de Silva et al. (2007), disponível no quadro anterior, aproveitando-se de seus méritos e 
de suas dificuldades. Leitores (as) não encontrarão no documento nada mais do que uma taxa de insucesso. Somente quando se tem acesso à base de dados da universidade é que se consegue observar alguma discriminação acerca das formas ou categorias de evasão. A UFU, para seu controle, registra as evasões a partir das categorias: 1) Desligamento, 2) Abandono $^{7}$, 3) Desistente, 4) Desistente Oficial, 5) Jubilamento ${ }^{8}$, 6) Cancelamento por indeferimento, 7) Cancelamento por indeferimento de renda, 8) Cancelamento de Matrícula - Mandado Segurança, 9) Transferência Interna, 10) Transferido e 11) Falecimento.

Observando-as na totalidade, tem-se a impressão de que se têm juntos marcadores de naturezas diferentes. Isolando as quatro primeiras, percebe-se o interesse de fazer o registro do modus operandi do desligamento, a forma de operacionalizar, sem valorar causas ou motivações. A quinta categoria, o jubilamento, guarda relação com o extrapolamento dos prazos de conclusão do curso que, naturalmente, remetem ao fenômeno da retenção que, por si só, já mereceria outra pesquisa. As categorias 6, 7 e 8 dizem respeito ao desligamento por descumprimento de preceito legal, acompanhado por processo administrativo ou judicial. Para que o vínculo seja desfeito nessas condições, o discente deveria ter conseguido se matricular de forma irregular, revelando, talvez, uma falha administrativa ou ações liminares. As de número 9 e 10 são mobilidades, tal como entendiam Ristoff (1999), Bueno (1993) e Cardoso (2008). Nesse caso, dados os argumentos expostos anteriormente, parece possivel dispensar mais linhas para demonstrar que as transferências não representariam, necessariamente, sinais de fracassos institucionais. No entanto, a motivação da transferência poderia indicar decepções com o curso ou com a instituição, mas para tanto, a caracterização da UFU também não jogaria luz sobre o fato, pois careceria de que o(a) discente apontasse suas razões. Por fim, o falecimento. Esse, muito embora tenha felizmente os menores números, somente em raríssimas circunstâncias teria nexo causal com a rotina institucional.

\section{Arriscando uma sugestão: considerações finais}

Pelo que se viu, a evasão é um indicador social cuja operacionalização da medida ou da mensuração tem acompanhado a generalidade da definição. Não cabe neste trabalho problematizar mais a mensuração, mas apontar, ao menos, uma possível saída para a definição. Ao que tudo indica, se a lacuna encontrada diz respeito à ausência da apresentação de causalidades para o fenômeno, parece que o caminho possível seria a realização de pesquisas com amostras significativas de evadidos. Tecnicamente, todas as IFES seriam capazes de empreender uma ação como essa, uma vez que há capacidade intelectual, registro das atividades acadêmicas, mecanismos de seleção, acesso à amostra e, por fim, potencial de análise.

Uma vez levantadas as razões, agregar-se-iam em grandes grupos por naturezas similares e ter-se-ia o retrato do fenômeno matizado, permitindo refletir acerca de

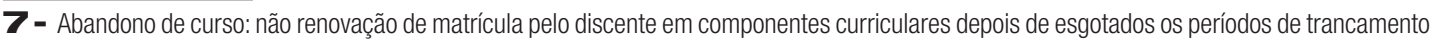
de matrícula.

$\boldsymbol{8}$ - Jubilamento: perda de vínculo com a UFU pela não conclusão do curso no tempo máximo previsto em seu Projeto Pedagógico ou por rendimento acadêmico insuficiente.
} 
ocorrências distintas e apontar soluções igualmente distintas. Como se pode observar, poucos foram os trabalhos acadêmicos que se dedicaram a mapear o fenômeno desta forma, e mais, pouca ou quase nenhuma é a influência desses sobre o processo de mensuração. Tem-se por óbvio que uma vez alterada a contabilidade da evasão, suas grandezas serão revistas, separando, a priori, aquilo que se pode chamar de um problema social, daquilo que não o seria.

Aproveitando as pesquisas que se dedicaram à busca dos nexos causais dos desligamentos, seria possível construir outros parâmetros para se pensar a evasão. Nesse diapasão, este artigo deixa como sugestão a utilização de uma nomenclatura alternativa. Não se deve perder de vista que se consolidou na academia e na gestão pública uma noção acerca da evasão. Para manter o diálogo com essa tradição, sem furtar-se da missão de incluir a preocupação que orienta este artigo, tomar-se-á a evasão como qualquer desligamento do curso, instituição ou sistema de ensino superior, entretanto se propõe uma tipologia necessária para ponderar sobre aquilo que deve ser tomado como problema social. Usada a tipologia, imagina-se que forçosamente uma cunha política e metodológica possa ser colocada no debate acerca deste tema.

Posto isso, chamar-se-ia de evasão por exclusão a perda do vínculo com o curso, instituição ou sistema de ensino superior originada pelas distorções institucionais em suas estruturas didáticas e curriculares ou por incapacidade institucional de combater as vulnerabilidades e garantir o direito à educação.

Tomada dessa forma, somente seria evasão por exclusão a perda de vínculo que se apresentar como um problema social, um fracasso institucional, uma incapacidade do Estado de garantir o acesso a um direito. Portanto, as iniciativas para a correção do problema recairiam sobre a própria instituição, sem trazer para si fenômenos que não são problemas, ou problemas que estão fora de sua alçada.

Por seu turno, seria chamado de evasão para inserção ${ }^{10}$ o trânsito de discentes entre cursos, instituições ou sistemas de ensino superior originado pela busca de novas oportunidades. Em se tratando de uma ação originada pela busca individual por novas oportunidades, sem vinculação direta com a qualidade do curso ou instituição e respondendo ao desejo humano da busca pela felicidade, tal movimento não seria tomado como um problema e, por conseguinte, não exigiria das instituições quaisquer iniciativas de correção.

Finalmente, sugere-se a denominação evasão por externalidades ${ }^{11}$ a perda de vínculo com o curso, a instituição ou o sistema de ensino superior por causas externas, involuntárias e de força maior.

9- Seriam possíveis motivadores da evasão por exclusão: prática pedagógica de docentes; currículos inchados, repetitivos e desarticulados; distanciamento entre teoria e prática; dificuldades na relação ensino-aprendizagem; poucas ou inacessíveis oportunidades acadêmicas; cultura institucional de desvalorização da docência na graduação; insuficiente estrutura de apoio ao ensino de graduação (laboratórios de ensino, equipamentos de informática etc.); insuficiente serviço de apoio ao ensino de graduação, vulnerabilidades sociais (renda, gênero, raça, violência, preconceito, discriminação, deficiência), maternidade e paternidade sem cobertura da assistência estudantil.

10- Seriam possíveis motivadores da evasão para inserção: baixo prestígio da profissão; baixos salários da profissão; pressão familiar ou de amigos (as); expectativa de futuro profissional; busca por segurança; descoberta de outros interesses.

11- Seriam possíveis motivadores para a evasão por externalidades: óbito, graves motivos de saúde, deslocamento familiar e territorial, problemas com a justiça. 
Não obstante pareça que a nova tipologia possa responder adequadamente ao propósito aqui levantado, sabe-se que seu teste de fogo deverá ocorrer em uma pesquisa empírica com evadidos, pela qual será possível observar seus impactos na mensuração e na avaliação das políticas públicas. Este teste está encomendado para a sequência e animará outro artigo em breve.

\section{Referências}

ABBAD, Gardênia; SILVEIRA CARVALHO, Renata; ZERBINI, Thaís. Evasão em curso via internet: explorando variáveis explicativas. RAE-eletrônica, São Paulo, v. 5, n. 2, 2006.

ADACHI, Ana Amelia Chaves Teixeira. Evasão e evadidos nos cursos de graduação da Universidade Federal de Minas Gerais. 2009. Dissertação (Mestrado em Educação) - Universidade Federal de Minas Gerais, Belo Horizonte, 2009.

ALMEIDA, João Batista; SCHIMIGUEL, Juliano. Avaliação sobre as causas da evasão escolar no ensino superior: estudo de caso no curso de licenciatura em física no Instituto Federal do Maranhão. Revista de Ensino de Ciências e Matemática, São Paulo, v. 2, n. 2, p. 167-178, 2012.

AMBIEL, Rodolfo A. M. Construção da escala de motivos para evasão do ensino superior. Avaliação Psicológica, Campinas, v. 14, n. 1, p. 41-52, 2015. Disponível em: http://pepsic.bvsalud.org/scielo. php?script=sci_arttext\&pid=S1677-04712015000100006. Acesso em: 04 jan. 2021.

ASSIS, Cristiano Ferreira de. Estudo dos fatores que influenciam a evasão dos alunos nos cursos superiores de tecnologia de uma instituição de ensino superior Privada. 2013. 91 p. Dissertação (Mestrado Profissional em Administração) - Fundação Cultural Dr. Pedro Leopoldo, Pedro Leopoldo, 2013.

BAGGl, Cristiane Aparecida dos Santos; LOPES, Doraci Alves. Evasão e avaliação institucional no ensino superior: uma discussão bibliográfica. Avaliação, Sorocaba, v. 16, n. 2, p. 355-344, 2011.

BARDAGI, Marucia; HUTZ, Claudio Simon. Evasão universitária e serviços de apoio ao estudante: uma breve revisão da literatura brasileira. Psicologia Revista, São Paulo, v. 14, n. 2, p. 279-301, 2014. Disponível em: https://revistas.pucsp.br/index.php/psicorevista/article/viewFile/18107/13463. Acesso em: 04 jan. 2021.

BONFIM, Edmar Ferreira Souto Mourão. Avaliação do rendimento e evasão de alunos cotistas e não cotistas da Universidade de Brasília. 2014. Trabalho de Conclusão de Curso. Departamento de Estatística. Universidade de Brasília, Brasília, 2014. Disponível em: http://bdm.unb.br/bitstream/10483/8675/1/2014_ EdmarFerreiraSoutoMourãoBonfim.pdf. Acesso em: 04 jan. 2021.

BRASIL. Decreto n 6.096, de 24 de abril de 2007. Institui o Programa de Apoio a Planos de Reestruturação e Expansão das Universidades Federais - REUNI. Brasília, DF: Presidência da República, 2007. Disponível em: http://www.planalto.gov.br/ccivil_03/_ato2007-2010/2007/decreto/d6096.htm. Acesso em: 04 jan. 2021.

BRASIL. Decreto n $^{\mathbf{7}}$ 7.234, de 19 de julho de 2010. Dispõe sobre o Programa Nacional de Assistência Estudantil - PNAES. Brasília, DF: Presidência da República, 2010. Disponível em: http://www.planalto.gov. br/ccivil_03/_ato2007-2010/2010/decreto/d7234.htm. Acesso em: 04 jan. 2021. 
BRASIL. Lei no 9.394, de 20 de dezembro de 1996. Estabelece as diretrizes e bases da educação nacional. Brasilia, DF: Congresso Nacional, 1996. Disponível em: http://www.planalto.gov.br/ccivil_03/leis/l9394. htm Acesso em: 04 jan. 2021.

BRASIL. Lei $\mathrm{n}^{\circ}$ 10.861, de 14 de abril de 2004. Institui o Sistema Nacional de Avaliação da Educação Superior - SINAES e dá outras providências. Brasília, DF: Presidência da República, 2004. Disponível em: http://www.planalto.gov.br/ccivil_03/_ato2004-2006/2004/lei/l10.861.htm. Acesso em: 04 jan. 2021.

CAMPELLO, Antonio de Vasconcellos Carneiro; LINS, Luciano Nadler. Metodologia de análise e tratamento da evasão e retenção em cursos de graduação de instituições federais de ensino superior. In: ENCONTRO NACIONAL DE ENGENHARIA DE PRODUÇÃO, 28., 2008, Rio de Janeiro. Anais... Rio de Janeiro: UFRJ, 2008. Disponível em: http://www.abepro.org.br/biblioteca/enegep2008_TN_ST0_078_545_11614.pdf Acesso em: 04 jan. 2021.

CARDOSO, Claudete Batista. Efeitos da política de cotas na Universidade de Brasília: uma análise do rendimento e da evasão. 2008. 134 f. Dissertação (Mestrado em Educação) - Universidade de Brasília, Brasília, 2008.

COSTA, Frederico Lustosa da; CASTANHAR, José Cezar. Avaliação de programas públicos: desafios conceituais e metodológicos. Revista de Administração Pública, Rio de Janeiro, v. 37, n. 5, p. 969-992, 2003. Disponível em: http://app.ebape.fgv.br/comum/arq/Costa_castanha.pdf. Acesso em: 04 jan. 2021.

DAVOK, Delsi Fries; BERNARD, Rosilane Pontes. Avaliação dos índices de evasão nos cursos de graduação da Universidade o Estado de Santa Catarina-UDESC. Avaliação, Sorocaba, v. 21, n. 2, p. 503-521, 2016.

FREITAS, Rafael Scarassatti. A ocorrência da evasão do ensino superior: uma análise das diferentes formas de mensurar. 2016. 82 p. Dissertação (Mestrado em Educação) - Universidade Estadual de Campinas, Faculdade de Educação, Campinas, 2016. Disponível em: http://www.repositorio.unicamp.br/ handle/REPOSIP/305324. Acesso em: 04 jan. 2021.

FURTADO, Vanessa Viégas Alves; ALVES, Tiago Wickstrom. Fatores determinantes da evasão universitária: uma análise com alunos da Unisinos. Contextus, Fortaleza, v. 10, n. 2, p. 115-129, 2012.

GAIOSO, Natalícia Pacheco de Lacerda. 0 fenômeno da evasão escolar na educação superior no Brasil. Brasília, DF: Universidade Católica de Brasília, 2005.

GILIOLI, Renato de Souza Porto. Evasão em instituições federais de ensino superior no Brasil: expansão da rede, SISU e desafios. Brasília, DF: Câmara dos Deputados, 2016. (Estudo técnico). Disponível em: http://nupe.blumenau.ufsc.br/files/2017/05/evasao_institui\%C3\% A7\%C3\%B5es.pdf Acesso em: 04 jan. 2021.

HOWLETT, Michael; RAMESH, M.; PERL, Anthony. Política pública: seus ciclos e subsistemas - uma abordagem integral. São Paulo: Campus, 2013.

INEP. Instituto Nacional de Estudos e Pesquisas Educacionais Anísio Teixeira. Instrumento de Avaliação Institucional Externa. Brasília, DF: INEP, 2017. 
INEP. Instituto Nacional de Estudos e Pesquisas Educacionais Anísio Teixeira. Orientações gerais para 0 roteiro da autoavaliação das Instituições. Brasília, DF: INEP, 2004.

INEP. Instituto Nacional de Estudos e Pesquisas Educacionais Anísio Teixeira. Sistema Nacional de Avaliação da Educação Superior (Sinaes). Brasília, DF: INEP, 2015. 5 v.

KIRA, Luci Frare. A evasão no ensino superior: o caso do curso de pedagogia da Universidade Estadual de Maringá (1992-1996). 1998. 106 p. Dissertação (Mestrado em Educação) - Universidade Metodista de Piracicaba, Piracicaba, 1998.

POLYDORO, Soely Aparecida Jorge. 0 trancamento de matrícula na trajetória acadêmica do universitário: condições de saída e de retorno a instituição. 2000. 175 f. Tese (Doutorado em Educação) Universidade Estadual de Campinas, Faculdade de Educação, Campinas, 2000. Disponível em: http://www. repositorio.unicamp.br/handle/REPOSIP/253539. Acesso em: 27 jul. 2018.

RANGEL, Flaminio de Oliveira et al. Evasão e vulnerabilidade acadêmica em um curso de formação de professores de ciências. In: ENCONTRO NACIONAL DE PESQUISA EM EDUCAÇÃO EM CIÊNCIAS - ENPEC, 9., 2013, Águas de Lindóia. Anais... Águas de Lindóia, 2013. Disponível em: http://abrapecnet.org.br/ atas_enpec/ixenpec/atas/resumos/R0284-1.pdf Acesso em: 04 jan. 2021.

RISTOFF, Dilvo Ilvo. Considerações sobre evasão. In: RISTOFF, Dilvo Ilvo. Universidade em foco: reflexões sobre a educação superior. Florianópolis: Insular, 1999. p. 119-130.

RISTOFF, Dilvo Ilvo. Considerações sobre a evasão. In: VASCONCELOS, Silvia Ines Coneglian Carrilho de (org.). Expressão sobre a graduação. Maringá: Universidade Estadual de Maringá, 1997. p. 09-32.

RODRIGUEZ, Alexandre. Fatores de permanência e evasão de estudantes do ensino superior privado brasileiro. In: SMPÓSIO DE EXCELÊNCIA EM GESTÃO E TECNOLOGIA, 8., 2011, Resende. Anais... Resende, 2011. Disponível em: https://www.aedb.br/seget/arquivos/artigos11/21514142.pdf. Acesso em: 04 jan. 2021.

SANTOS, Georgina Gonçalves dos; SILVA, Lélia Custódio da. A evasão na educação superior: entre debate social e objeto de pesquisa. In: SAMPAI0, Sônia Maria Rocha (org.). Observatório da vida estudantil: primeiros estudos. Salvador: UFBA, 2011. p. 249-262. Disponível em: http://books.scielo.org/id/n656x/ pdf/sampaio-9788523212117-14.pdf. Acesso em: jan. 2021.

SANTOS JUNIOR, José da Silva. Aspectos conceituais e metodológicos sobre evasão na educação superior. In: REUNIÃO NACIONAL DA ANPEd, 37., 2015, Florianópolis, 2015. Anais... Florianópolis: Anped, 2015b. Disponível em: http://37reuniao.anped.org.br/wp-content/uploads/2015/02/P\%C3\%B4ster-GT11-4117. pdf Acesso em: 04 jan. 2021.

SANTOS JUNIOR, José da Silva. Trajetória acadêmica de estudantes de graduação: evasão, permanência e conclusão de cursos na Universidade Federal da Grande Dourados. 2015. 166 f. Dissertação (Mestrado em Educação) - Universidade Federal de Grande Dourados, Dourados, 2015a.

SANTOS JUNIOR, José da Silva et al. Análise estatística da evasão na Universidade Federal do Espírito Santo e uma avaliação de seus determinantes. In: SIMPÓSIO BRASILEIRO DE PESQUISA OPERACIONAL, 
2015, Porto de Galinhas. Anais... Porto de Galinhas: [s. n.], 2015. Disponível em: http://www.din.uem.br/ sbpo/sbpo2015/pdf/142900.pdf. Acesso em: 20 out. 2017

SANTOS JUNIOR, José da Silva et al. Fatores associados à evasão e conclusão de cursos de graduação presenciais na UFES. Revista Meta, Rio de Janeiro, v. 8, n. 24, p. 488-514, 2016.

SECCHI, Leonardo. Análise de políticas públicas: diagnóstico de problemas, recomendação de soluções. 1. ed. São Paulo: Cengage Learning, 2016.

SESU/MEC; ANDIFES; ABRUEM. Diplomação, retenção e evasão nos cursos de graduação em IES públicas: Comissão Especial de Estudos sobre a Evasão nas Universidades Públicas Brasileiras. Brasília, DF: [s. n.], 1996. Disponível em: http://www.andifes.org.br/wp-content/files_flutter/Diplomacao_Retencao_ Evasao_Graduacao_em_IES_Publicas-1996.pdf. Acesso em: 04 jan. 2021.

SILVA FILHO, Roberto Leal Lobo et al. A evasão no ensino superior brasileiro. Cadernos de Pesquisa, São Paulo, v. 37, n. 132, p. 641-659, 2007.

TINTO, Vincent. Dropout from higher education: A theoretical synthesis of recent research. Review of Educational Research, Washington, DC, v. 45, n. 1, p. 89-125, 1975.

VELLOSO, Jacques Rocha; CARDOSO, Claudete Batista. Evasão na educação superior: alunos cotistas e não cotistas na Universidade de Brasília. In: REUNIÃO NACIONAL DA ANPEd, 31., 2008, Caxambu. Anais... Caxambu: Anped, 2008. Disponível em: https://www.anped.org.br/biblioteca/item/evasao-na-educacaosuperior-alunos-cotistas-e-naocotistas-na-universidade-de. Acesso em: 04 jan. 2021.

VELOSO, Tereza Christina M. A.; ALMEIDA, Edson Pacheco de. Evasão nos cursos de graduação da Universidade Federal de Mato grosso, Campus Universitário de Cuiabá: um processo de exclusão. Estudos, Campo Grande, n. 13, p. 133-148, 2002. Disponível em: https://www.serie-estudos.ucdb.br/serie-estudos/ issue/view/31. Acesso em: 04 jan. 2021.

Recebido em: 15.09.2019

Aprovado em: 12.11.2019

Camila Lima Coimbra é professora da Faculdade de Educação da Universidade Federal de Uberlândia (UFU), graduada em pedagogia e mestre em educação pela UFU e doutora em educação pela Pontifícia Universidade Católica de São Paulo (PUC/SP). É pesquisadora do Grupo de Pesquisa Observatório de Políticas Públicas da UFU.

Leonardo Barbosa e Silva é professor do Instituto de Ciências Sociais da Universidade Federal de Uberlândia (UFU), graduado em ciências econômicas pela UFU, mestre e doutor em sociologia pela Universidade Estadual Paulista Júlio de Mesquita Filho (UNESP). Atualmente é docente do Programa de Pós-Graduação em Ciências Sociais da UFU. Foi pró-reitor de assistência estudantil e hoje lidera o Grupo de Pesquisa Observatório de Políticas Públicas da UFU. 
Natália Cristina Dreossi Costa é mestranda do Programa de Pós-Graduação do Instituto de Ciências Sociais da Universidade Federal de Uberlândia (UFU). É bacharel e licenciada em ciências sociais pela UFU. É integrante do Grupo de Pesquisa Observatório de Políticas Públicas da UFU. 